\title{
INADEQUACIES OF CONTRACEPTIVE SERVICES IN ENGLAND AND WALES
}

\author{
ANN GARTWRIGHT \\ Institute for Social Studies in Medical Care, \\ 18 Victoria Park Square, Bethnal Green, London E2 9PF
}

There is clear evidence from a number of different sources that many women are becoming pregnant when they do not want to be. A conscientious or religious objection to contraception seems to be the reason for only a small proportion of these unintended pregnancies. Distaste for present contraceptive techniques and the absence of an acceptable and reliable contraceptive, which is felt to be free from health hazards, constitute one basic problem. The inadequacies of existing contraceptive services account for another. The main part of this paper discusses the deficiencies of present services and suggests ways in which they might be improved.

\section{EVIDENCE OF INADEQUACIES}

In a survey of mothers of legitimate babies in 1967-68, $15 \%$ said they felt 'sorry it happened at all' when they first found they were pregnant. A further $17 \%$ would have preferred the pregnancy 'rather later'. Just over a quarter were attempting some form of birth control around the time they became pregnant. The picture in early 1970 was similar (Cartwright, 1970).

In addition to the unintended legitimate births there are the illegitimate ones: $8 \%$ of all births in 1970 . Not all of them will be unintended but the proportion of pregnancies that are initially unwelcome is likely to be higher than among those resulting in legitimate births.

Finally, there is the evidence of the number of legal abortions that are carried out. Others will have been requested, but not performed. In 1970-71 a random sample of general practitioners estimated that a third of their referrals for abortion under the National Health Service were turned down (Cartwright \& Waite, 1972).

\section{ATTITUDES TO BIRTH CONTROL}

Most people approve of the idea of birth control. Although Roman Catholics are less likely to do so than others, more than half the Roman Catholic mothers surveyed in 1967-68 were in favour of contraception, a quarter had mixed feelings and one in eight were against it. Mothers who were against birth control were not less likely to feel 'sorry it happened at all' about their last pregnancy, but they were less likely to be using any method of birth control. They both had and wanted larger families, hence religious or other objections to birth control account for only a small proportion of unwanted pregnancies. 
Almost all women, excluding those involuntarily childless, now use some form of birth control at some stage in their married life (Glass, 1968). And a P.E.P. study of women having abortions showed that the majority, about two-thirds, were attempting to restrict their fertility around the time they became pregnant (Williams \& Hindell, 1972). Thus, the main problem is not that many people disapprove of birth control and never attempt to use any method of contraception; it is rather that people often do not use methods consistently and many use unreliable techniques. They are ineffective, not unwilling, users of contraception.

\section{USE AND VIEWS OF DIFFERENT METHODS}

In 1967-68, the birth control techniques most commonly used by parents 4 to 7 months after the birth of a baby were the sheath, $36 \%$; withdrawal, $21 \%$; the pill, $20 \%$; the safe period, $6 \%$; the cap, $5 \%$; and the IUD, 3\%. In February 1970 the position was similar except that the proportion who had been sterilized had risen from $2 \%$ to $5 \%$ (Cartwright, 1970). Other studies report similar findings (Glass, 1968; Woolf, 1971).

Use of relatively unreliable methods, such as withdrawal and the safe period, clearly contributes substantially to the incidence of unintended pregnancies. Mothers' views of the advantages and disadvantages of various methods of

Table 1. Mothers' perceptions of the advantages and disadvantages of various methods of contraception in 1967-68

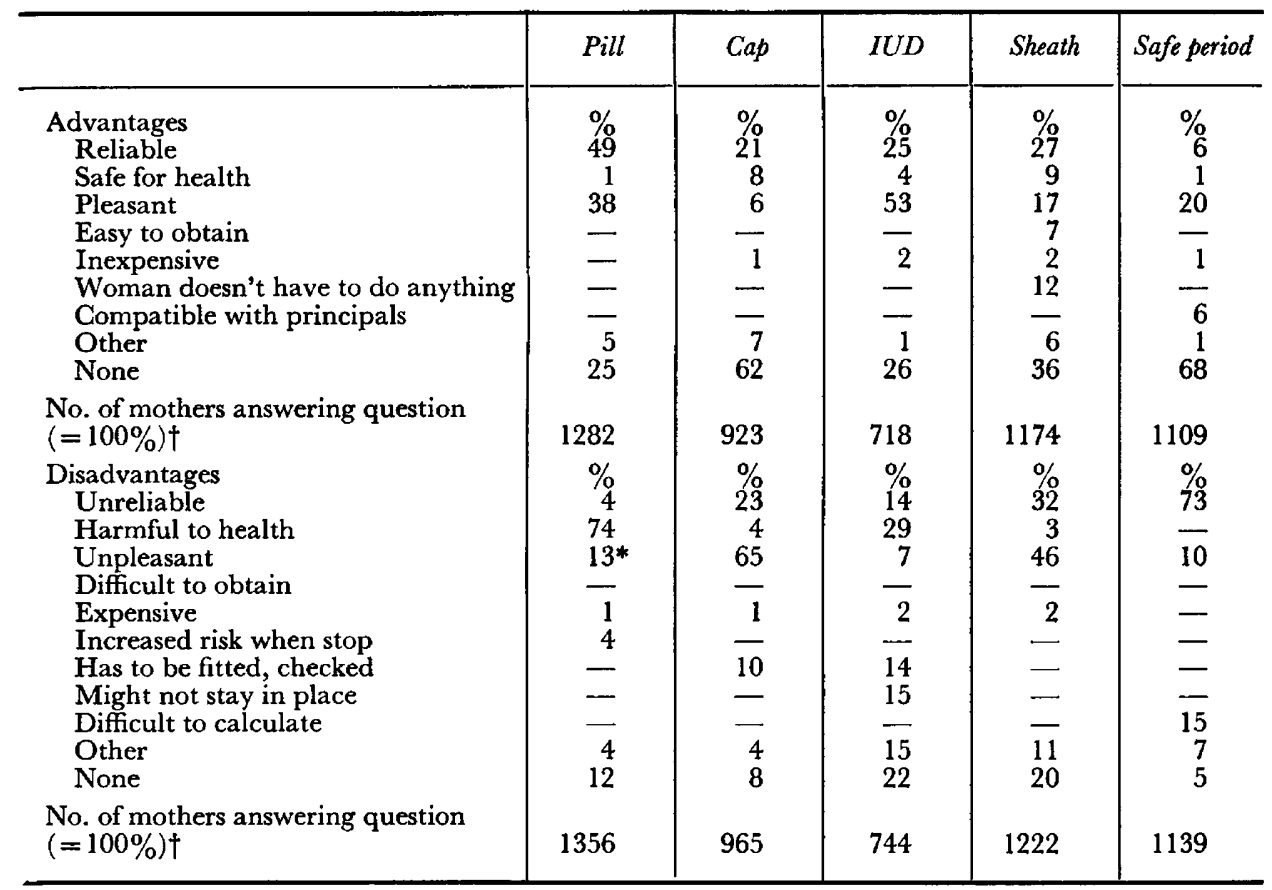

* These were mainly mothers who mentioned the problem of remembering to take the pill.

$\dagger$ Different numbers answered the two questions about advantages and disadvantages. 
contraception are shown in Table 1. Fathers' views were broadly similar. Most women regard the pill as a risk to health, the safe period as unreliable and the cap as unpleasant to use. Considerable numbers felt the sheath was unpleasant to use or unreliable. Rather less than half could tell us any advantages or disadvantages of the IUD. Their most frequent comment about it was the advantage of not having to do anything once it had been inserted.

Among mothers currently using different methods, those taking the pill or fitted with an IUD were most likely to describe the method as very satisfactory. This is shown in Table 2.

Table 2. Mothers' views of the methods they were using

\begin{tabular}{|c|c|c|c|c|c|}
\hline \multirow[b]{2}{*}{ Opinion } & \multicolumn{5}{|c|}{ Mothers using } \\
\hline & $\begin{array}{l}\text { Pill } \\
(\%)\end{array}$ & $\begin{array}{l}\text { Cap } \\
(\%)\end{array}$ & $\begin{array}{l}I U D \\
(\%)\end{array}$ & $\begin{array}{l}\text { Sheath } \\
(\%)\end{array}$ & $\begin{array}{l}\text { Safe period } \\
(\%)\end{array}$ \\
\hline $\begin{array}{l}\text { Very satisfactory } \\
\text { Fairly satisfactory } \\
\text { Rather unsatisfactory } \\
\text { Very unsatisfactory }\end{array}$ & $\begin{array}{l}89 \\
\frac{10}{1}\end{array}$ & $\begin{array}{r}48 \\
48 \\
4 \\
-\end{array}$ & $\begin{array}{l}74 \\
26 \\
- \\
-\end{array}$ & $\begin{array}{r}41 \\
49 \\
9 \\
1\end{array}$ & $\begin{array}{r}33 \\
33 \\
29 \\
5\end{array}$ \\
\hline $\begin{array}{l}\text { No. of mothers using } \\
\text { method }(=100 \%)\end{array}$ & 290 & 67 & 46 & 521 & 84 \\
\hline
\end{tabular}

These data on use and views of different techniques suggest that, although only $3 \%$ of mothers of young babies had an IUD fitted, more would be interested in this method of contraception if it were more readily available. But it is clear that there is no method generally felt to be reliable, pleasant to use and free from health hazards. For most couples, the choice of contraceptive is a compromise. A range of methods should be available and information about them readily accessible. Society and the medical profession need to recognize and accept that if a theoretically less reliable method is more acceptable it may be more effective in practice.

\section{INADEQUATE SERVICES}

Present birth control services are inadequate on a number of counts. One is their concentration on female methods of contraception and almost total neglect of male methods. Yet, when a sample of mothers and fathers were asked whether 'other things being equal' (that is reliability, cost, health risks, pleasantness and accessibility) they would prefer a method in the man's or the woman's control, their views were very evenly divided (see Table 3 ).

Professionals may feel that people do not need advice about non-medical methods. But they could be advised on how to use them more effectively. Of the mothers who reported use of the sheath, $85 \%$ said they did not use any lubricants or spermicides (Cartwright, 1971).

The limited amount of advice given by professionals constitutes another shortcoming of the present services. General practitioners, by far the most frequent source of professional help, tend to equate birth control with the pill, 
and their concentration on this single method seems to be increasing. In 1967-68 $77 \%$ of them said this was the method they most often advised; by 1970-71, the figure had risen to $90 \%$. There has been no dramatic change in the proportions fitting IUDs: $10 \%$ in 1967-68, 12\% in 1970-71 (Cartwright, 1970; Cartwright \& Waite, 1973).

Table 3. Preference for methods in the man's or woman's control*

\begin{tabular}{l|c|c}
\hline & Mothers (\%) & Fathers (\%) \\
\hline Prefer method in: & & \\
Man's control & 46 & 49 \\
Woman's control & 41 & 41 \\
Do not mind or other answer & 13 & 10 \\
\hline No. of parents (=100\%) & 1442 & 250 \\
\hline
\end{tabular}

* After Cartwright (1970).

In addition, the present services are unevenly distributed. There tend to be few clinics available in the less well-off areas (Cartwright, 1970), and there are wide variations in the amount of help given by general practitioners (Cartwright, 1970; Cartwright \& Waite, 1973), health visitors (Cartwright, 1970; Waite, 1972a) and domiciliary midwives (Waite, 1972b) with different religious affiliations. For example, in 1970-71 25\% of Roman Catholic general practitioners never prescribed the pill, less than $1 \%$ of other doctors (Cartwright \& Waite, 1973).

An obvious reason for the limited help and advice given by general practitioners and by hospital doctors is their lack of education and training in this field; many now in practice received their medical education before the contraceptive pill was developed or IUDs became respectable. But even as recently as 1965-66, a study of final year medical students showed that only a minority were given any teaching in contraceptive methods which included contact with patients (Simpson, 1969). Only $2 \%$ of more than 400 hospital consultants in obstetrics and gynaecology, surveyed in 1971, thought the training of junior doctors in contraceptive techniques before coming to their department was good; $23 \%$ described it as adequate and $69 \%$ as insufficient; $6 \%$ said they did not know (M. Waite, unpublished data).

Only very recently and probably greatly stimulated by the Abortion Act have many obstetric departments in hospitals been much concerned with contraception. In $1967-68$, only $12 \%$ of a sample of mothers with young babies said they had had any discussion of birth control methods with a doctor at a hospital. The proportion was less than one in ten of those having their first or second baby but rose to two-fifths, still less than half, of those having their sixth child or more (Cartwright, 1970). In 1971, three-quarters of hospital consultants in obstetrics thought the subject of birth control should be raised routinely with all maternity patients (M. Waite, unpublished data).

In my view it is important that doctors in hospital and general practice should 
offer patients advice about birth control without waiting for the patients to raise the subject. This was the opinion of $71 \%$ of the mothers interviewed in 1967-68. The others thought that people would ask for advice if they wanted it, but many with the majority view described the diffidence and embarrassment they or others might feel in raising the topic with a doctor.

Between 1967-68 and 1970-71, the proportion of general practitioners who said they would raise the subject of birth control with an unmarried woman who had had a baby increased from $51 \%$ to $73 \%$. But even at the later date only a third said they would raise it with a married woman with three children if she had no social or health problems. The majority still view their rôle in birth control as limited to aiding patients who ask for help and offering advice to those with health or social problems (Cartwright \& Waite, 1973).

Although the general practitioner was the most frequent source of professional help, nearly half the mothers of young children seen in 1967-68 felt that a specialist clinic was a more suitable place to get advice initially. But long distances to travel, infrequent sessions and lengthy waits were a common experience of women attending clinics. It took a fifth of them half an hour or more to get to the clinic; for two-fifths, an opportunity to attend the nearest clinic occurred only once a week or less often; more than a third of the mothers attending clinics had to wait an hour or more, a tenth waited for at least $2 \mathrm{hr}$ (Cartwright, 1970). Easy accessibility on all three counts is essential if clinics are to meet the potential demand for their services.

The inadequacy of present clinic facilities is one of the detrimental effects of relying mainly on a voluntary organization for the provision of such services. An even greater disadvantage is the lack of integration between services that results from this arrangement.

\section{PROBLEMS OF NON-INTEGRATION}

The most obvious and significant weakness of birth control services at the moment is that they are not fully integrated into the National Health Service. This is not only illogical but leads to poor organization and communication between different branches of the service. It also affects the status and image of birth control among the medical and nursing professions and in the community.

Specialist services need to be linked with the general practitioners and the health visitors. People giving primary care will always be in a key position to identify those in need of help, but they need specialist support, particularly when developments in contraceptive techniques are so rapid. The basic rôle of the specialist in birth control should be to inform, encourage and support the primary care givers; ensuring that they are kept up-to-date with relevant developments and have opportunities to discuss the implications of new trends. The specialists could encourage general practitioners, for example, to see their rôle in relation to birth control more widely.

The people in many ways most appropriately placed to take on this specialist rôle are doctors working at family planning clinics, but until they are fully integrated into the National Health Service they cannot do this effectively.

Some evidence of the stimulation that might result from a fully integrated service comes from a survey of health visitors in 1970-71. Those who worked 
from a Maternity and Child Health Centre, where there was also a family planning clinic, were more active in offering advice about birth control (Waite, 1972a). In many ways, health visitors seem well placed to play an important rôle in advising mothers of young children about contraception: they are women, and they visit all mothers in their own homes after they have had a baby. Nevertheless only $13 \%$ of the mothers interviewed in 1967-68 said they had ever discussed methods of birth control with a health visitor. In an integrated service, doctors specializing in birth control could encourage and educate health visitors to play a more active rôle. Certainly three-quarters of health visitors, in 1967-68, thought they should actively promote family planning education (Cartwright, 1970). A quarter of those interviewed in 1970-71 said they would like to know more about some methods of contraception (Waite, 1972a). Health visitors might also be asked by either clinic doctors or general practitioners to give support and encouragement to people starting to use a new method they were rather hesitant about, or to follow up those not coming for prescriptions or 'check-ups' when expected.

Another aspect of the rôle of the expert in birth control could be to act as an instigator of services. He could be concerned, for instance, with the wide-scale distribution and easy accessibility of condoms-persuading supermarkets to stock them, encouraging the installation of slot-machines in suitable public places and ensuring that such machines are refilled and serviced; empty condom machines are reputed to be a source of revenue as many would-be customers will not complain if they do not get anything for their money. Such activities are clearly appropriate when undertaken under the auspices of the local health authority or their successors but are unlikely to be the concern of a voluntary organization with limited funds obtained mainly from clinic users.

A further disadvantage of clinics being run by a voluntary organization is that, in spite or because of its long history of devoted service by pioneers, it has acquired an aura of 'good works' and middle-class feminism which is not a helpful or appropriate image for present-day services. The condescension that professionals are apt to feel towards voluntary organizations tends to spill over to the objectives of those organizations. Family planning may then be seen as a suitable activity for voluntary women workers and correspondingly devalued and deprived of professional status. Doctors, whose education is hospitaloriented towards the curing of disease, may have their prejudices against preventive and social care in the community reinforced by these reactions.

It is time birth control services were organized in a way more related to presentday needs. Full integration with the National Health Service is an essential prerequisite to a more rational and effective service.

To sum up, the main developments I would like to see in contraceptive services are, firstly, that full responsibility for such services should be taken over by the national health and local authority health services. Local Authorities should run their own birth control clinics in conjunction with their Maternity and Child Welfare Centres and these should be staffed by health visitors and doctors employed directly by the Local Health Authority. The clinics will need to have evening as well as day-time sessions. 
Secondly, not only should there be more local authority clinics but hospitals should be encouraged to have their own clinics and offer help to all maternity and abortion patients. General practitioners and health visitors should also be encouraged to give advice. Supermarkets could be persuaded to stock sheaths (women could pick up the spare packet so next time their husbands forget they do not have to take a chance). Slot machines for condoms in pubs and public lavatories should be encouraged, supervised and serviced. It is not a question of whether birth control advice and help is most appropriately given by general practitioners, health visitors, midwives or school teachers; or whether it is most appropriately given in hospitals, clinics, consulting rooms, people's homes or supermarkets. It should be available at all these sources.

Thirdly, doctors and nurses should offer help without waiting to be asked and they should give information and advice about a wider range of contraceptive techniques. Facilities for fitting IUDs should be increased.

Fourthly, if general practitioners are not prepared to advise patients about birth control, and prescribe the pill, alternative arrangements should be made for their patients to get help about this. Whether doctors are willing to provide this service might be indicated in local lists of doctors which are available to the public and which, at the moment, state whether he gives maternity services. Doctors unwilling to give birth control advice should not work in a singlehanded practice but with other doctors who are prepared to give this type of help to other patients in the practice. In future it might be reasonable to say that people who are not willing to offer advice on birth control should not become health visitors.

Fifthly, students need to know not only the techniques but to be aware of the effects of contraceptive failure, the diffidence many patients have about raising the subject and the problems of helping people select the method which is likely to be most appropriate for them. Such students need to be continuously brought up-to-date about technical developments in contraceptive techniques and research findings. Small local seminars with the doctors and nurses together would probably be an appropriate way to do this as they could discuss their approaches and views together.

Lastly, there should be further research on alternative methods of contraception, with particular emphasis on possible male methods.

\section{REFERENCES}

Cartwright, A. (1970) Parents and Family Planning Services. Routledge \& Kegan Paul, London.

Cartwright, A. (1971) Family planning and professional advice. Contemp. Review. 218, 8.

Cartwright, A. \& Waite, M. (1972) General practitioners and abortion. F. R. Coll. Genl Practitioners, Vol. 22, Suppl. No. 1 .

Cartwright, A. \& Waite, M. (1973) General practitioners and contraception in 1970/71. F. R. Coll. Genl Practitioners. Vol. 22, Suppl. No. 1.

GLass, D. V. (1968) Contraception in marriage. Family Planning, 17, 55.

Simpson, P. (1969) Teaching in family planning 1965-66. Br. F. med. Educ. 3, 84.

WaITE, M. (1972a) Health visitors and birth control advice 1970-71. Nurs. Times 12th and 19th October.

Warte, M. (1972b) Domiciliary midwives and birth control advice 1970-71. Nurs. Times 7 th and 14th December.

Williams, H. \& Hindell, K. (1972) Abortion and Contraceptives: a Study of Patients' Attitudes. P.E.P. Broadsh. 536.

WooLf, M. (1971) Family Intentions. An Enquiry Undertaken for the General Register Office. Office of Population Censuses and Surveys. Social Survey Division, Report M.408. HMSO, London. 